\title{
APLICAÇÃO DE LACTATO DE CÁLCIO E ÁCIDO ASCÓRBICO NA CONSERVAÇÃO DE MINIMILHO MINIMAMENTE PROCESSADO
}

\author{
Application of calcium lactate and ascorbic acid in the conservation \\ of babycorn minimally processed
}

\author{
Kelen Cristina dos Reis ${ }^{1}$, Joelma Pereira ${ }^{2}$, Luiz Carlos de Oliveira Lima ${ }^{2}$, \\ Renzo Garcia Von Pinho ${ }^{3}$, Augusto Ramalho de Morais ${ }^{4}$
}

\begin{abstract}
RESUMO
O minimilho é uma forma especial de consumo não industrializado do milho, que consiste de espigas jovens que são utilizadas dois ou três dias após a exposição dos cabelos da espiga, os chamados estilo-estigmas. Com este trabalho teve-se como objetivo avaliar o uso de lactato de cálcio e de ácido ascórbico no processamento mínimo de minimilho e verificar as possíveis alterações do produto durante o armazenamento. Estudaram-se as características físicas, fisico-químicas, químicas e bioquímicas. O experimento foi realizado no Departamento de Ciência dos Alimentos da Universidade Federal de Lavras, MG e conduzido em delineamento inteiramente casualizado, com três repetições. Os tratamentos foram dispostos em fatorial 3x5, constituídos pela imersão do minimilho em água destilada, lactato de cálcio $1 \%$ e ácido ascórbico $1 \%$ e armazenados por 0 , 3, 6, 9 e 12 dias a $5^{\circ} \mathrm{C}$ e 90\% U.R.. O tratamento com ácido ascórbico resultou em aumento no teor de vitamina C no minimilho minimamente processado, sugerindo que esse ácido foi eficientemente absorvido pelos tecidos. As espiguetas tratadas com lactato de cálcio e ácido ascórbico obtiveram armazenamento por 12 dias.
\end{abstract}

Termos para indexação: Zea mays, vitamina C, embalagem.

\begin{abstract}
The babycorn is a special form of not industrialized consumption of the corn, that consists of young spikes that are used two or three days after the exhibition of the hair of the spike, called style-stigmas. This work had as objective to evaluate the effects of calcium lactate and ascorbic acid on fresh-cut babycorn and to verify the possible alterations of the product during storage. Physical, physico-chemical, chemical and biochemical, characteristics were studied. The experiment was carried out in the Food Science Department at Federal University of Lavras, MG and conduct in completely randomized design, with three replicates. Treatments were arranged in a factorial 3x5, scheme constituted by the immersion of babycorn in distilled water, calcium lactate (1\%), ascorbic acid (1\%) and stored for 0, 3, 6, 9 and 12 days $\left(5^{\circ} \mathrm{C}\right.$ and $\left.90 \% \mathrm{RH}\right)$. Treatment with ascorbic acid increased the amount vitamin $\mathrm{C}$ in the minimally processed babycorn, suggesting it was absorbed by the tissue. The young ear treated with calcium lactate and ascorbic acid, had a shelf life of 12 days.
\end{abstract}

Index terms: Zea mays, vitamin $\mathrm{C}$, packing.

(Recebido para publicação em 3 de outubro de 2003 e aprovado em 5 de novembro de 2004)

\section{INTRODUÇÃO}

Nos últimos anos, tem-se enfatizado a necessidade do consumo de frutas e hortaliças frescas, buscando-se uma dieta saudável e, ao mesmo tempo, há uma demanda crescente de alimentos mais convenientes, frescos, que sejam menos processados e estejam prontos para o consumo.

O milho é um dos cereais mais utilizados na cadeia alimentícia, sob diversas formas. Uma forma especial de consumo não industrializado desse cereal é o minimilho. Nesse caso, as espigas jovens são utilizadas no estágio de dois ou três dias após a exposição dos cabelos da espiga (estilo-estigmas). O minimilho, é similar às demais hortaliças quanto à sua composição, apresentando cerca de $89,1 \%$ de umidade; $0,20 \%$ de gordura; 1,90\% de proteína; 8,20\% de carboidratos e 0,06\% de cinzas. Em 100 gramas do minimilho, têm-se, em média, $28 \mathrm{mg}$ de cálcio; $86 \mathrm{mg}$ de fósforo; 0,10 mg de ferro; 0,05 $\mathrm{mg}$ de tiamina; 0,80 $\mathrm{mg}$ de riboflavina; $11,0 \mathrm{mg}$ de ácido ascórbico e 0,30 mg de niacina. Das necessidades diárias recomendadas de nutrientes, $100 \mathrm{~g}$ de minimilho fornecem $13 \%$ de potássio, $14 \%$ de vitamina B6, 17\% de vitamina C e $11 \%$ de fibras (PEREIRA FILHO et al., 1998).

\footnotetext{
1. Doutoranda em Ciência dos Alimentos no Departamento de Ciências dos Alimentos/DCA - UFLA -Caixa Postal 3037 - $37200-000$ - Lavras,MG kelen.cristina@zipmail.com.br

2. Professor (a) Adjunto do Departamento de Ciência dos Alimentos/UFLA

3. Professor Adjunto do Departamento de Agronomia/UFLA.

4. Professor Adjunto do Departamento de Ciências Exatas/ UFLA.
} 
As condições de clima e solo brasileiras são propícias ao cultivo de minimilho. A Tailândia é o maior produtor e vem dominando o mercado tanto com produto fresco quanto processado. A produção de minimilho no Brasil está apenas começando, sendo destinada à indústria de alimentos enlatados, conservas e produtos frescos. Desse modo, é de grande importância a realização de pesquisas que possibilitarão maior eficiência no processamento do minimilho, com o objetivo de se estender a sua vida pós-colheita mantendo características de frescor pelo uso de uma série de parâmetros de conservação, como: baixa temperatura, embalagem, boas práticas de higiene e sanitização e tratamentos químicos.

Entre os tratamentos químicos mais utilizados, estão a utilização de cálcio e de ácido ascórbico. O cálcio desempenha um papel importante na manutenção da qualidade de frutas e hortaliças. Além das desordens fisiológicas, o cálcio está associado à própria qualidade, com efeitos sobre a respiração e a textura e também acha-se relacionado a diversas doenças de natureza microbiana. O ácido ascórbico (vitamina C) é um dos principais antioxidantes para uso em frutas e hortaliças para prevenir escurecimento e outras reações oxidativas (CARVALHO \& CHALFOUN, 1991).

$\mathrm{O}$ alimento minimamente processado apresenta características, em geral, mais próximas da forma in natura, comparado aos que são processados de forma convencional. Esses produtos são submetidos a operações de limpeza, lavagem, sanificação, seleção, descascamento, corte, embalagem e armazenamento, podendo ou não sofrer tratamentos químicos, prolongando, assim, sua vida de prateleira. O processamento mínimo de minimilho vem despertando interesse. No entanto, não está muito difundido no Brasil, talvez por falta de maiores informações sobre seu processamento, apresentando enorme potencial.

Com este trabalho teve-se como objetivo avaliar a utilização de lactato de cálcio e ácido ascórbico no processamento mínimo de minimilho e verificar as possíveis alterações físicas, fisico-químicas, químicas e bioquímicas que ocorreram durante o armazenamento.

\section{MATERIAL E MÉTODOS}

\section{Procedência das amostras}

Para a realização do experimento, foi utilizada a cultivar de minimilho DKB 929. Os procedimentos de plantio, tratos culturais e colheita foram realizados nos campos experimentais do Departamento de Agricultura (DAG), no campus da Universidade Federal de Lavras
(UFLA), em Lavras, Minas Gerais. O experimento foi conduzido durante os anos de 2001 e 2002, sendo a semeadura em 30 de novembro de 2001.

De acordo com Carvalho (2002), a cultivar DKB 929, tradicionalmente utilizada para produção de grãos, apresentou melhor desempenho para a produção de minimilho, independente da época de semeadura e do local considerado. De todas as cultivares estudadas, essa foi a mais produtiva, com valores de produção sempre superiores a 1,5 t.ha $^{-1}$.

\section{Coleta e preparo das amostras}

A colheita foi realizada logo após o aparecimento dos estilos-estigmas (cabelos), de acordo com a recomendação de Magda (1995). A colheita foi manual, realizada nas primeiras horas da manhã. As espiguetas, após serem colhidas, foram transportadas em caixas de isopor com água gelada a $5^{\circ} \mathrm{C}$ para o Departamento de Ciência dos Alimentos. Em seguida, foram lavadas em água potável e sanificadas em água gelada $\left(5^{\circ} \mathrm{C}\right.$ a $\left.8^{\circ} \mathrm{C}\right)$ com 100 ppm de hipoclorito de sódio, por 5 minutos. Foram então descascadas manualmente, com facas afiadas de aço inoxidável, para remoção da palha, dos cabelos e dos resíduos da planta de milho.

As espiguetas foram então padronizadas, como é feito para a comercialização, ou seja, tamanho entre 4 $\mathrm{cm}$ e $10 \mathrm{~cm}$; em seguida, foram sanificadas por imersão em solução de hipoclorito de sódio (10 ppm) por 15 minutos, tendo a água utilizada para a solução sido previamente resfriada $\left(5^{\circ} \mathrm{C}-8^{\circ} \mathrm{C}\right)$. Após a sanificação, foram aplicados os seguintes tratamentos por imersão em solução, durante 5 minutos: controle: água destilada; ácido ascórbico 1\%; lactato de cálcio $1 \%$.

As amostras, após a realização dos respectivos tratamentos, foram deixadas para que escorresse o excesso de água, por 3 minutos e, em seguida, foram divididas aleatoriamente e acondicionadas em embalagens de poliestireno (PS), envolvidas com filme plástico esticável, espessura $20 \mu \mathrm{m}$, autoadesivo, de policloreto de vinila (PVC). As bandejas foram então armazenadas em câmara fria a $5 \pm$ $1^{\circ} \mathrm{C}$ e $90 \pm 1 \%$ de UR, por um período de 12 dias. As análises físicas, físico-químicas, químicas e bioquímicas foram realizadas no tempo zero (dia da colheita) e em intervalos de 3 dias, até o período de 12 dias de armazenamento. A unidade experimental constou de cinco bandejas.

Foram retiradas amostras para as análises físicas de força de cisalhamento e cor. Uma outra parte foi homogeneizada com auxílio de um microprocessador doméstico e utilizada para as análises de acidez total titulável, sólidos solúveis totais, pH, extração para análise 
da vitamina $C$ total, compostos fenólicos, açúcares totais, redutores e não-redutores e amido. $\mathrm{O}$ restante das amostras foi acondicionado em sacos de polietileno, congelado em nitrogênio líquido e mantido a $18^{\circ} \mathrm{C}$, para análises de atividade enzimática (polifenoloxidase e peroxidase).

\section{Análises físicas, físico-químicas, químicas e bioquímicas}

Acidez total titulável (ATT) - padronizada segundo técnica estabelecida pelo AOAC (1990).

pH - segundo técnica da AOAC (1992).

Sólidos solúveis totais (SST) - segundo AOAC (1992).

Açúcares totais, redutores e não redutores. - determinados pelo método redutométrico de Somogy, adaptado por Nelson (1944).

Vitamina C total - segundo Strohecker \& Henning (1967). Atividade enzimática da polifenoloxidase (PFO) - técnica descrita por Ponting \& Joslyn (1948), citados por Tomé (2002), com modificações para minimilho. O resultado da atividade enzimática por minuto, com base na massa fresca, foi expresso em 1 ๆmol por grama de amostra $\left(\eta m o l \cdot g^{-1} \cdot \mathrm{min}^{-1}\right)$.

Valor $\mathrm{L}^{*}$ (Luminosidade) - $\mathrm{O}$ valor $\mathrm{L}^{*}$ foi determinado em duas faces da amostra de cada repetição, utilizando-se colorímetro Minolta, modelo Chroma Meter CR 3000 .

\section{Delineamento experimental e análise estatística}

O experimento foi conduzido em delineamento inteiramente casualizado, com três repetições, com os tratamentos dispostos em esquema fatorial $3 \times 5$. Os tratamentos foram constituídos pelas combinações entre as soluções de imersão em 3 tratamentos [água destilada (controle), lactato de cálcio 1\%, ácido ascórbico 1\%] e com os períodos de armazenamento de $0,3,6$,9 e 12 dias. A unidade experimental constou de cinco bandejas de aproximadamente $100 \mathrm{~g}$ cada uma.

Os resultados das características avaliadas foram submetidos à análise de variância, com auxílio do programa SISVAR (FERREIRA, 2000). Para a descrição das variáveis em função dos períodos de armazenamento, foram feitas análises de regressão considerando os tempos de armazenamento, como a variável independente e as características avaliadas como a variável dependente.

\section{RESULTADOS E DISCUSSÕES}

\section{Acidez total titulável}

A ATT mostrou-se afetada significativamente pela interação entre os diferentes tratamentos e o tempo de armazenamento. Pode-se observar, na Figura 1 , que houve um aumento nos teores de ATT durante o período de armazenamento para os três tratamentos. De modo geral, a acidez cresce paralelamente à velocidade da hidrólise do amido. O tratamento com ácido ascórbico resultou em maiores índices de acidez total titulável nos tempo 0, 3 e 12 dias (Figura 1).

\section{pH}

Não foi observada interação significativa entre os tratamentos utilizados e o tempo de armazenamento; no entanto, os tratamentos e os tempos de armazenamento afetaram os teores de $\mathrm{pH}$. Durante o período de armazenamento, os valores de $\mathrm{pH}$ apresentaram oscilações, variando de 5,67 até 6,08.

As espiguetas tratadas com ácido ascórbico apresentaram menores valores de $\mathrm{pH}(5,74)$ em relação às espiguetas do tratamento controle $(5,91)$ e às espiguetas tratadas com lactato de cálcio $(5,93)$ (Figura 2).

Tomé (2002) encontrou valores de $\mathrm{pH}$ variando de 6,25 a 6,40, quando trabalhou com espiguetas de minimilho DKB 929 minimamente processadas e armazenadas por 12 dias. Carvalho (2002) encontrou valores de 6,42 a 6,95 para as cultivares Zélia e Elisa, respectivamente, valores esses superiores ao encontrado neste trabalho, que foi de 5,85.

\section{Sólidos solúveis totais}

Os valores de SST apresentaram oscilações em relação ao tempo de armazenamento devido, provavelmente, à síntese e consumo de substratos, respectivamente, no metabolismo respiratório dos vegetais (Figura 3).

Inúmeros fatores podem influenciar o teor de SST. O valor observado para SST representa o teor de açúcares, ácidos orgânicos e outros constituintes menores. Portanto, decréscimos nos valores dessa variável representam teores mais baixos em um ou mais constituintes que compõem os SST. 


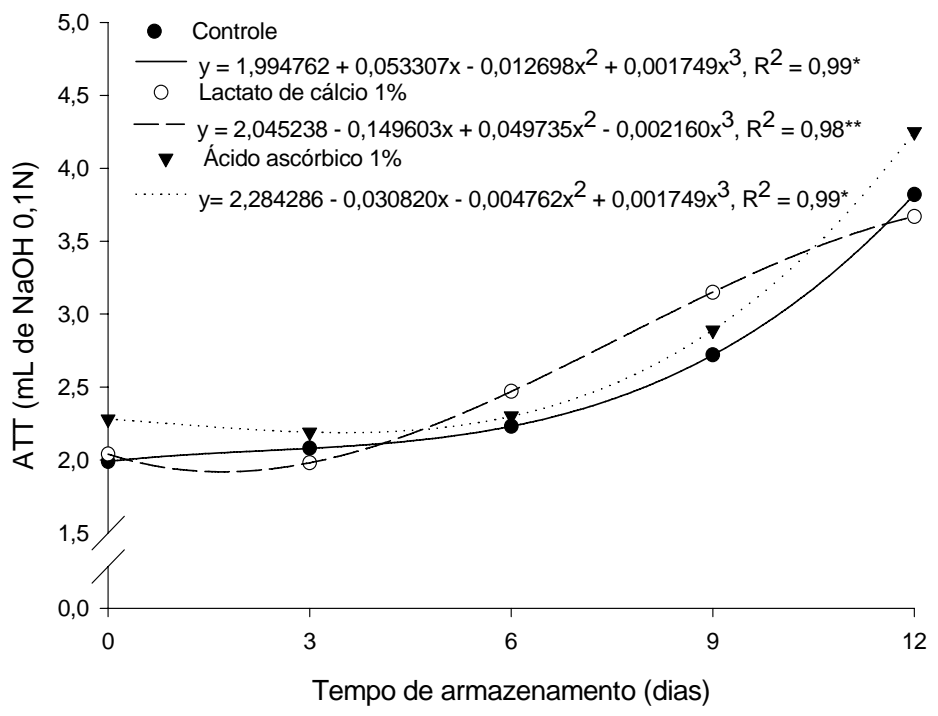

FIGURA 1 - Representação gráfica e equações de regressão da acidez total titulável (ATT) em minimilho minimamente processado, para os diferentes tratamentos (controle, lactato de cálcio $1 \%$ e ácido ascórbico 1\%), em função do tempo de armazenamento sob condições refrigeradas ( $5 \pm 1^{\circ} \mathrm{C}$ e $90 \pm 1 \%$ de UR).

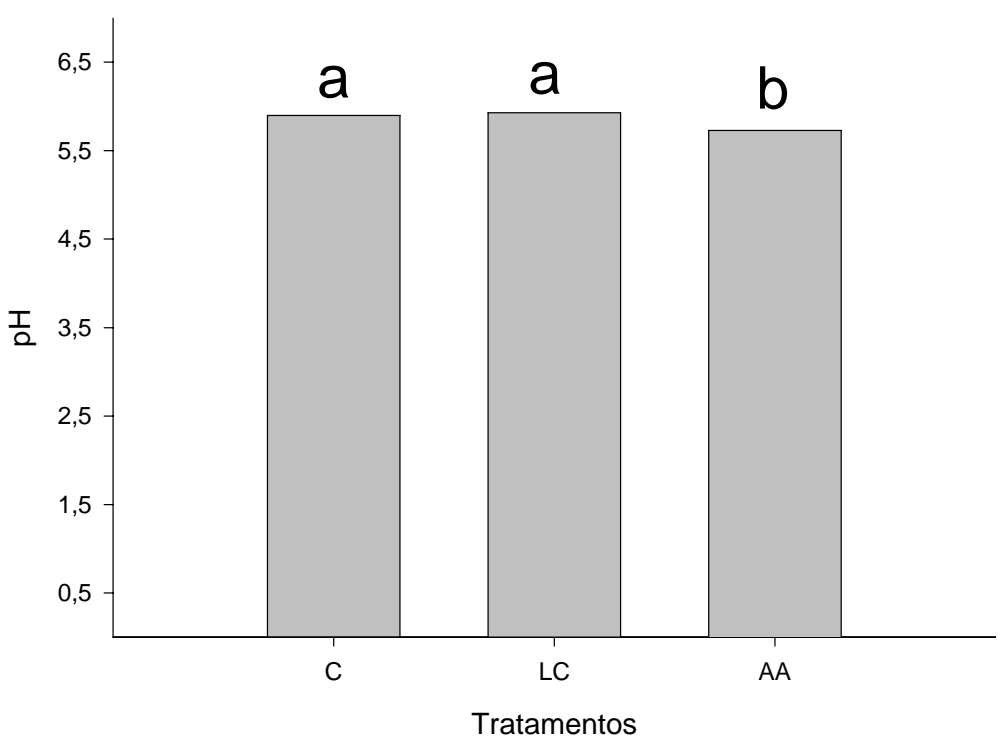

FIGURA 2 - Valores médios de pH de minimilho minimamente processado, para os diferentes tratamentos [controle (C), lactato de cálcio 1\% (AC) e ácido ascórbico 1\% (AA)], em função do tempo de armazenamento sob condições refrigeradas $\left(5 \pm 1^{\circ} \mathrm{C}\right.$ e $90 \pm 1 \%$ de UR). 


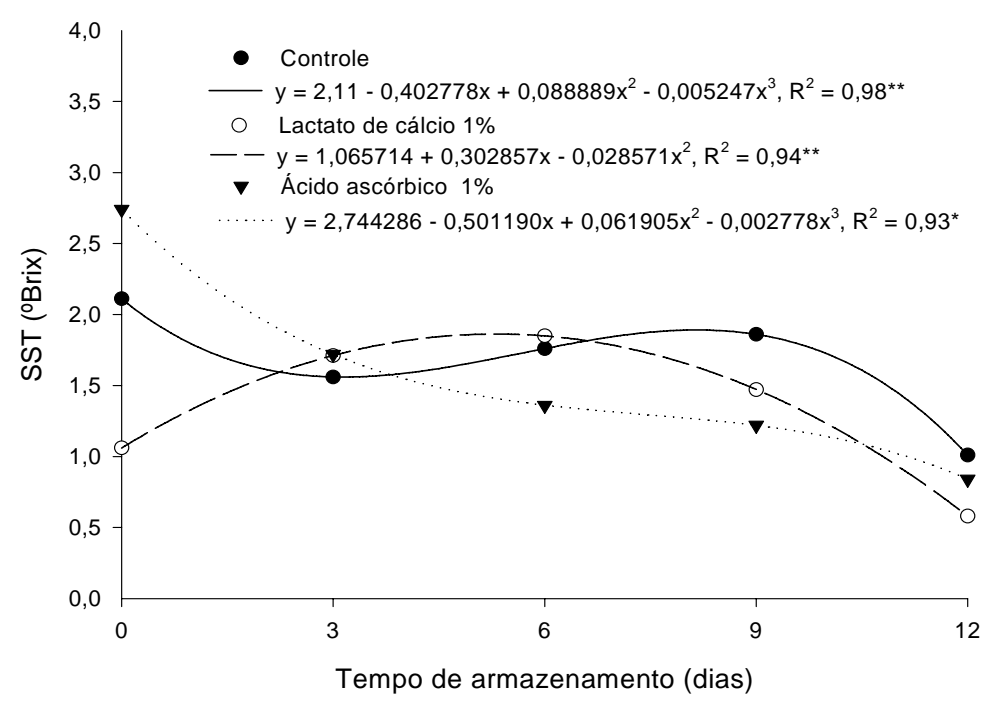

FIGURA 3 - Representação gráfica e equações de regressão de sólidos solúveis totais (SST) em minimilho minimamente processado, para os diferentes tratamentos (controle, lactato de cálcio $1 \%$ e ácido ascórbico 1\%), em função do tempo de armazenamento sob condições refrigeradas ( $5 \pm 1^{\circ} \mathrm{C}$ e $90 \pm 1 \%$ de UR).

\section{Açúcares totais, redutores e não-redutores}

O teor médio de açúcares totais foi de 2,93 g. $100 \mathrm{~g}^{-1}$, valor inferior ao encontrado por Tomé (2002), que quantificou, na mesma cultivar destinada à produção de minimilho, o teor médio de 4,49 g. $100 \mathrm{~g}^{-1}$ .Os valores encontrados para os teores de açúcares totais estão próximos àqueles encontrados por Bar-Zur \& Schaffer (1993), que quantificaram, em cultivar doce destinada à produção de minimilho, índices médios de 2 a 3 g.100 ${ }^{-1}$ de açúcares totais. De acordo com Tomé (2002), o nível de açúcares acumulados decresce com o aumento da temperatura e a ressíntese de amido.

Bar-Zur \& Schaffer (1993) observaram valores médios de 10 a 15 mg.g ${ }^{-1}$ de açúcares redutores. Esses resultados estão abaixo do que foi encontrado neste trabalho (2,15 g.100g $\left.\mathrm{g}^{-1}\right)$. Verificaram-se oscilações nos teores de açúcares não-redutores durante o armazenamento para os todos os tratamentos (Figura 4), com os maiores teores ocorrendo no $6^{\circ}$ dia quando se usou lactato.

Os valores encontrados para os teores de açúcares não-redutores $\left(0,75 \mathrm{~g} \cdot 100 \mathrm{~g}^{-1}\right)$ estão acima dos encontrados por Carvalho (2002) e Tomé (2002), com valores médios de 0,54 g. $100 \mathrm{~g}^{-1}$ e $0,58 \mathrm{~g} \cdot 100 \mathrm{~g}^{-1}$, respectivamente.

\section{Vitamina C}

As espiguetas tratadas com ácido ascórbico apresentaram teores mais elevados de vitamina $\mathrm{C}$ quando comparadas às demais (Figura 5).
Os teores de vitamina $\mathrm{C}$ variaram durante $\mathrm{o}$ período de armazenamento. Observa-se, na Figura 5, que as espiguetas tratadas com ácido ascórbico apresentaram um decréscimo nos teores de vitamina $\mathrm{C}$ durante o período de armazenamento. Isso se deve talvez à oxidação do ácido ascórbico. O principal mecanismo que causa perda de vitamina $C$ em alimentos é iniciado pela oxidação do ácido L-ascórbico pelo oxigênio $\left(\mathrm{O}_{2}\right)$ catalizada por íons $\mathrm{Fe}(\mathrm{III})$ e $\mathrm{Cu}$ (II) e o produto resultante é o ácido dehidroascórbico, que retém o potencial vitamínico (TOMÉ, 2002). As espiguetas do tratamento-controle e as tratadas com lactato de cálcio tiveram diferenças mínimas quanto ao teor de ácido ascórbico e esses teores variaram ligeiramente durante o armazenamento.

\section{Atividade da polifenoloxidase (PFO)}

Houve efeito significativo somente do tempo de armazenamento sobre a atividade da enzima PFO, a qual mostrou uma redução até o $9^{\circ}$ dia de armazenamento, seguida depois de um aumento até o $12^{\circ}$ dia (Figura 6).

De acordo com Tomé (2002), a perda da atividade da polifenoloxidase pode ser explicada pelo uso do filme de PVC de $20 \mu \mathrm{m}$ que revestiu as embalagens com as espiguetas. O filme contribui para uma baixa concentração de oxigênio, resultando na diminuição da oxidação dos compostos fenólicos como substratos para a enzima até o $9^{\circ}$ dia de armazenamento. 


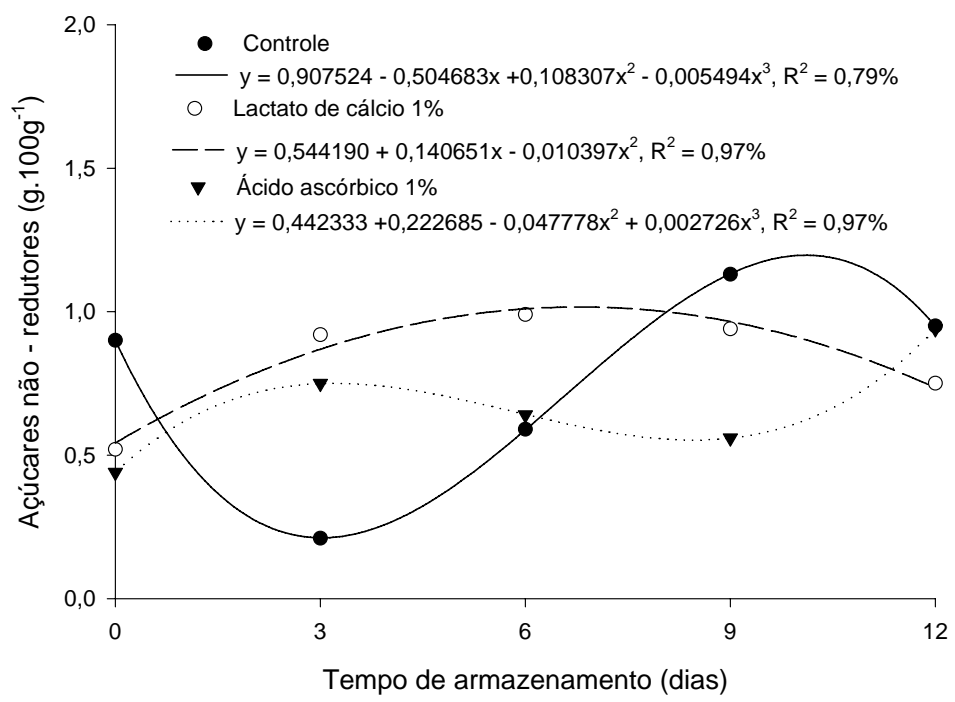

FIGURA 4 - Representação gráfica e equações de regressão dos teores de açúcares não-redutores em minimilho minimamente processado, para os diferentes tratamentos (controle, lactato de cálcio 1\% e ácido ascórbico 1\%), em função do tempo de armazenamento sob condições refrigeradas $\left(5 \pm 1^{\circ} \mathrm{C}\right.$ e $90 \pm 1 \%$ de UR).

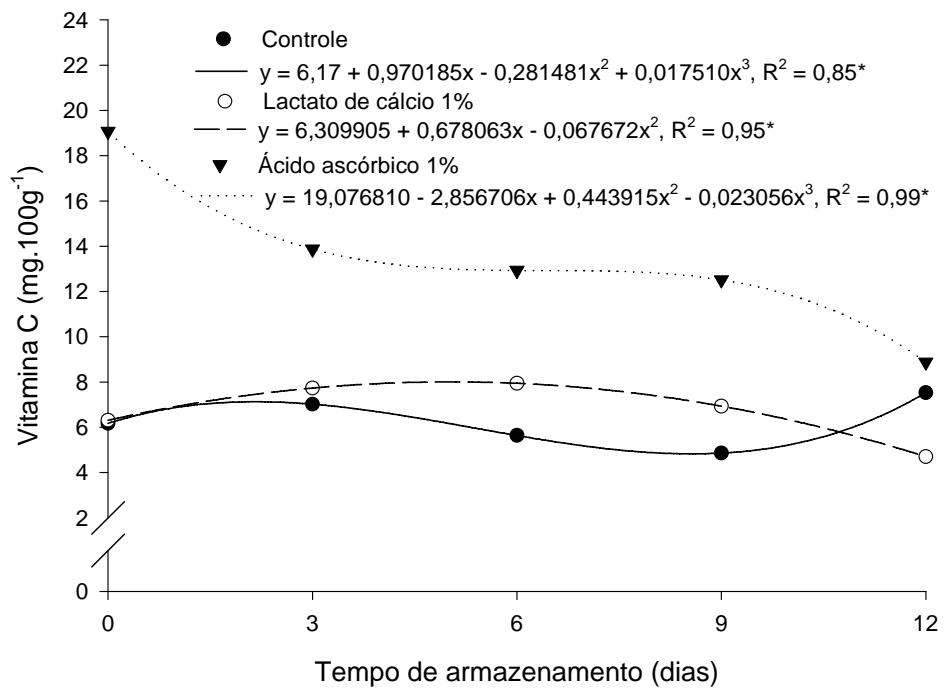

FIGURA 5 - Representação gráfica e equações de regressão de vitamina C em minimilho minimamente processado, para os diferentes tratamentos (controle, lactato de cálcio 1\% e ácido ascórbico 1\%), em função do tempo de armazenamento sob condições refrigeradas $\left(5 \pm 1^{\circ} \mathrm{C}\right.$ e $90 \pm 1 \%$ de UR). 


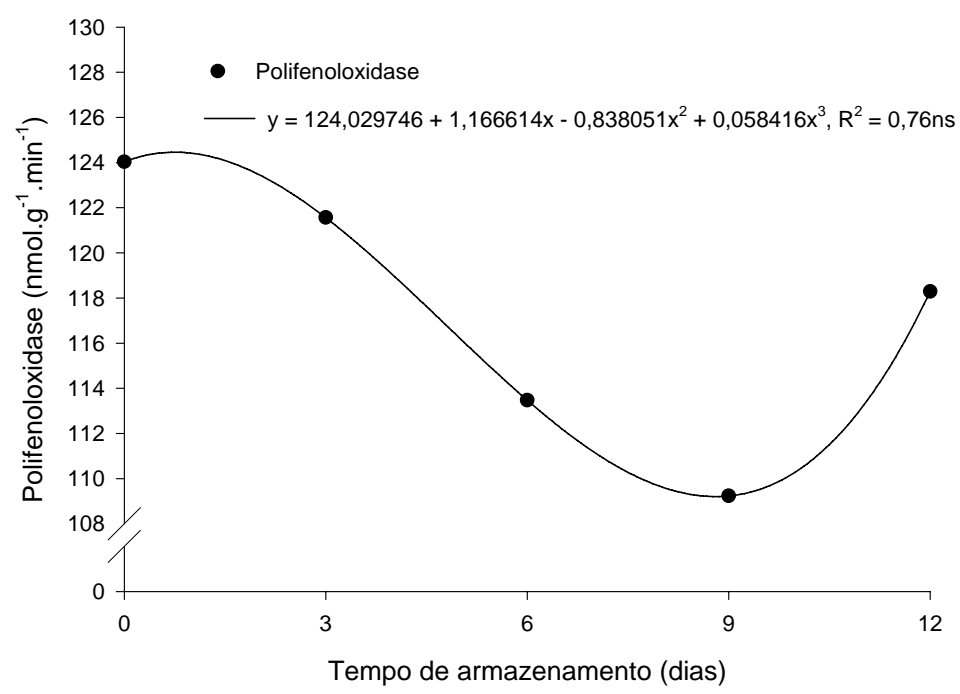

FIGURA 6 - Representação gráfica e equação de regressão da atividade da polifenoloxidase em minimilho minimamente processado, para os diferentes tratamentos (controle, lactato de cálcio 1\% e ácido ascórbico 1\%), em função do tempo de armazenamento sob condições refrigeradas $\left(5 \pm 1^{\circ} \mathrm{C}\right.$ e $90 \pm 1 \%$ de UR).

\section{Valor L* -Luminosidade}

Segundo a análise de variância, não houve influência significativa dos tempos de armazenamento e nem na interação entre tratamentos e tempos de armazenamento sobre a luminosidade ( $\left.\mathrm{L}^{*}\right)$.

O minimilho apresentou-se de cor forte e brilhante durante todo o período de armazenamento, independente do tratamento utilizado; as amostrascontrole também apresentaram alta luminosidade (72,74). A ausência de escurecimento no minimilho minimamente processado pode ser explicada pela presença de alto teor de ácido ascórbico que, por si próprio, previne a oxidação de muitos polifenóis.

$\mathrm{O}$ valor médio encontrado neste trabalho para luminosidade foi de 72,57, o que não corresponde ao apresentado por Tomé (2002), um valor médio de 22,43 para amostras de minimilho de três cultivares.

\section{CONCLUSÕES}

a) Sob condições refrigeradas, o minimilho minimamente processado tem sua aparência e firmeza mantidas durante 12 dias de armazenamento.

b) $\mathrm{O}$ armazenamento a $5^{\circ} \mathrm{C}$ e $90 \%$ de UR foi efetivo na manutenção dos níveis de açúcares.

c) Não foram observados aumentos nos índices de cálcio nos frutos submetidos ao tratamento com lactato de cálcio. d) O tratamento com ácido ascórbico aumentam o teor de vitamina $\mathrm{C}$ no minimilho minimamente processado.

e) Minimilho minimamente processado tratado com solução de lactato de cálcio a 1\% e ácido ascórbico a $1 \%$ alcança uma vida de prateleira de 12 dias, se armazenados a $5^{\circ} \mathrm{C}$ e $90 \%$ de UR.

\section{REFERÊNCIAS BIBLIOGRÁFICAS}

ASSOCIATION OF OFFICIAL ANALITICAL CHEMISTS. Official methods of analysis of the Association of Agricultural Chemists. 10. ed. Washington, 1990. $1015 \mathrm{p}$.

ASSOCIATION OF OFFICIAL ANALITICAL CHEMISTS. Official methods of analysis of the Association of Agricultural Chemists. 12. ed. Washington, 1992. $1015 \mathrm{p}$.

BAR-ZUR, A.; SCHAFFER, A. Size and carbohydrate content of ears of baby corn in relation to endosperm ty (su, su, se, sh2). Journal of American Society Horticultural Sciences, Alexandria, v. 118, n. 1, p. 141-144, Jan. 1993.

CARVALHO, G. S. Caracterização agronômica e nutricional de cultivares de milho sob diferentes condições de cultivo para produção de minimilho 2002. 70 p. Dissertação (Mestrado em Agronomia) - Universidade Federal de Lavras, Lavras, 2002. 
CARVALHO, V. D.; CHALFOUN, S. M. A importância do cálcio na agricultura. Informe Agropecuário, Belo Horizonte, v. 15, n. 170, p. 1728, 1991.

FERREIRA, D. F. Análise estatística por meio dos SISVAR para Windows versão 4.0. In: REUNIÃO ANUAL DA REGIÃO BRASILEIRA DA SOCIEDADE INTERNACIONAL DE BIOMETRIA, 45., 2000, São Carlos. Anais... São Carlos: UFSCar, 2000. p. 255-258.

MAGDA, R. R. Tender juice baby corn. Food Marketing \& Tecnology, Noremberg, v. 9, n. 3, p. 4-6, May/June 1995.
NELSON, N. A. A photometric adaptation of Somogyi method for the determination of glucose. The Journal of Biological Chemistry, Baltimore, v. 135, n. 1, p. 136-175, June 1944.

PEREIRA FILHO, I. A.; GAMA, E. E. G.; LEMOS FURTADO, A. A. Produção do minimilho. Brasília: EMBRAPA, 1998. 4 p. (Comunicado Técnico, 7).

STROHECKER, R.; HENNING, H. M. Analisis de vitaminas: métodos comprobados. Madrid: Paz Montalvo, 1967. 428 p.

TOMÉ, P. H. Avaliação das cultivares de milho normal, doce e pipoca visando o processamento mínimo de minimilho. 2002. 89 p. Tese (Doutorado em Ciência dos Alimentos) - Universidade Federal de Lavras, Lavras, 2002. 